\title{
EFFECTS OF Li-SUBSTITUTION ON HIGH-K INDUCED CONTRACTIONS OF VARIOUS SMOOTH MUSCLE TISSUES IN THE GUINEA-PIG
}

\author{
Tadashi KISHIMOTO and Norimoto URAKAWA \\ Department of Veterinaly Pharmacology. Faculty of Agriculture. \\ University of Tokyo, Bunkyo-ku. Tokyo 113, Japan
}

Accepted February 17, 1982

\begin{abstract}
The effects of partial Li-substitution for external $\mathrm{Na}$ in the medium on contraction, cellular Li concentration, and ${ }^{45} \mathrm{Ca}$ uptake of various smooth muscle tissues depolarized by a high-K $(62.7 \mathrm{mM})$ solution were studied. In the taenia coli and ileum isolated from the guinea-pig. Li-substitution (23.7 $\mathrm{mM}-59.4 \mathrm{mM}$ ) increased the cellular $\mathrm{Li}$ concentration and strongly inhibited the K-contraction. A good correlation between cellular Li concentration and inhibition of tension was obtained in both the taenia coli and ileum. In the portal vein and uterus, Li-substitution inhibited K-contraction in correlation with $\mathrm{Li}$-accumulation, although the inhibitory effect was weaker than those obtained with the taenia coli and ileum. In the aorta. $\mathrm{Li}$-substitution did not affect $\mathrm{K}$-contraction in spite of the accumulation of $\mathrm{Li}$. The inhibitory effects of Li-substitution in all the tissues except the aorta were antagonized by an increase in external $\mathrm{Ca}$, and the inhibition was accompanied by a decrease in cellular ${ }^{45} \mathrm{Ca}$ content. Although there is a tissue-specific defference, a possibility exists that excess cellular Li inhibits the $\mathrm{K}$-induced $\mathrm{Ca}$ influx. The $\mathrm{K}$-induced $\mathrm{Ca}$ influx in the aorta seems to be almost insensitive to the inhibitory effect of cellular Li.
\end{abstract}

Previous studies have shown that partial Li substitution for external $\mathrm{Na}$ in the medium can inhibit the tonic contraction of guinea-pig taenia coli induced by high $\mathrm{K}(1-4)$. It has also been reported that the $\mathrm{Ca}$-induced contractile response was inhibited by a partial substitution of $\mathrm{Li}$ for $\mathrm{Na}$ in high-K solution in the longitudinal and circular muscles of guinea-pig stomach (5) and in the rat uterus $(6,7)$. In our recent paper (8), we reported that $\mathrm{Li}$-induced relaxation of the guinea-pig taenia coli in high-K solution was closely correlated with an increase in cellular Li. The observation suggests that the

A preliminary report on this study was presented at the Eighth International Congress of Pharmacology in Tokyo (1981). increased intracellular Li in some way inhibits the high- $\mathrm{K}$ induced inward movement of $\mathrm{Ca}$. Therefore, there may be also a correlation between the increase in cellular $\mathrm{Li}$ and the inhibition of $\mathrm{K}$-contraction in different smooth muscle tissues.

In the present study, we clarify the properties of the mechanical response in the guinea-pig taenia coli, ileum, portal vein, aorta, and uterus to various $K$-concentrations. We have investigated the effect of partial Li-substitution on the $62.7 \mathrm{mM} \mathrm{K}$-induced contraction in these muscles, and the results are compared with each other. Experiments have been performed to study tension development, extracellular space, dry weight/ wet weight, cellular Li concentration, and 
${ }^{45} \mathrm{Ca}$ uptake following the treatment with $\mathrm{Li}$. Some important and interesting differences are detected in the various types of smooth muscle preparations.

\section{MATERIALS AND METHODS}

Most of the materials and methods were the same as described in our preceding paper (9). The muscle preparations used were the taenia coli, ileum, portal vein, aorta, and uterus isolated from the guinea-pig. Normal physiological salt solution (PSS) contained $(\mathrm{mM}): \mathrm{NaCl}, 136.8 ; \mathrm{KCl}, 5.4 ; \mathrm{CaCl}_{2}, 2.5$; $\mathrm{MgCl}_{2}, 1.0 ; \mathrm{NaHCO}_{3}, 11.9$, and glucose, 5.5. In the experiment with varing concentrations of external $\mathrm{K}$, the external $\mathrm{Na}$ concentration was modified by substituting $\mathrm{Na}$ salts by an equivalent amount of $K$ salts. In most experiments, however, the high- $\mathrm{K}(62.7 \mathrm{mM})$ solution was made by increasing $\mathrm{KCl}$ to $62.7 \mathrm{mM}$ and reducing $\mathrm{NaCl}$ to $106.8 \mathrm{mM}$. An application of Li was made by substituting $\mathrm{LiCl}$ for an equivalent amount of $\mathrm{NaCl}$ in the high- $K$ solution.

The contractile tension of muscle strips was isometrically recorded with a straingauge transducer (Nihon Kohden). After incubation with the test solution, the muscles were exposed to a Na-solution ( $\mathrm{NaCl}$, 169.5: $\mathrm{CaCl}_{2}, 2.5 ; \mathrm{MgCl}_{2}, 1.0 ; \mathrm{NaHCO}_{3}$. 11.9 and glucose. $5.5 \mathrm{mM}$ ) at $0.5^{\circ} \mathrm{C}$ for $30 \mathrm{~min}$ in order to remove extracellular $\mathrm{Li}$. The size of the extracellular space (ECS) was determined by the uptake of an extracellular space maker, ${ }^{14} \mathrm{C}$-sorbitol $(2 \mu \mathrm{Ci} / \mathrm{ml}$, The Radiochemical Centre, England). Tissue Li content was measured by flame photometry using a method similar to that described by Kishimoto and Urakawa (8), and cellular Li concentration was estimated from the values of ECS and dry weight/wet weight. ${ }^{45} \mathrm{Ca}$ uptake into the muscle cells was measured by a modified "La-method" which was developed by Karaki and Weiss (10). The drugs used were verapamil (Eisai), atropine sulphate. propranolol hydrochroride (Tokyo Kasei), phentolamine methylate (Ciba Geigy), and $\beta$-estradiol (Sigma).

\section{RESULTS}

A. Responses to varing concetrations of external K: The muscle strips of the taenia coli, ileum, portal vein, and uterus have spontaneous mechanical activity, but that of the aorta does not (Fig. 1). The spontaneous activity of each muscle in normal solution
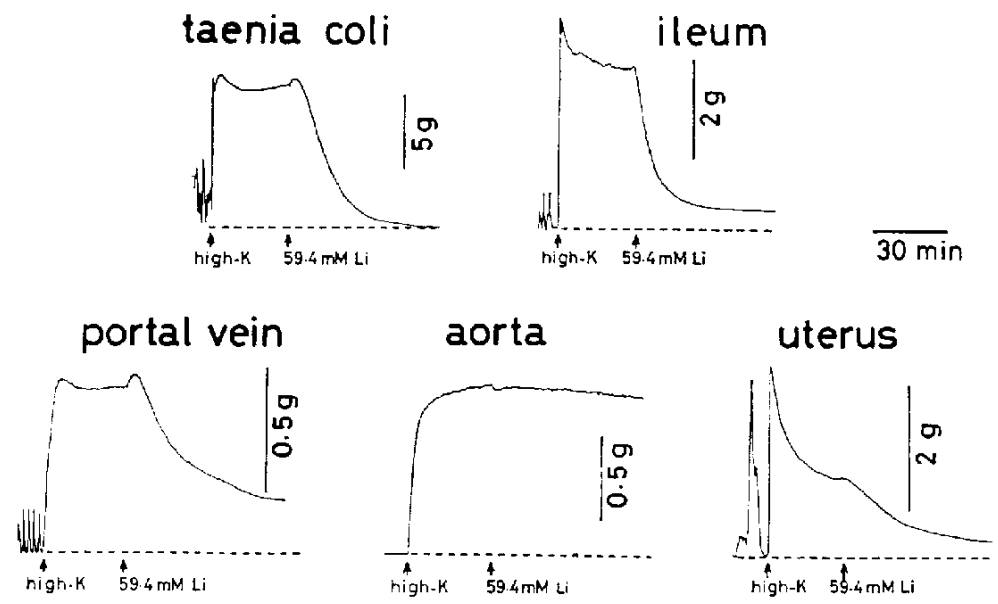

Fig. 1. Effects of Li-substitution $(59.4 \mathrm{mM})$ on $\mathrm{K}$-contractions in the taenia coli, ileum, portal vein, aorta, and uterus. 
consists of a phasic contraction occurring at almost regular intervals, and the magnitude of the phasic contraction increased by slightly raising external $K$. Further raising external $K$ resulted in a tonic contraction subsequent to the phasic contraction. On the other hand, the aorta generated a tonic contraction without a phasic one. As shown in Fig. 1. exposure of the taenia coli, ileum, portal vein, and uterus to high-K (62.7 mM) solution resulted in a rapid phasic contraction (within $1 \mathrm{~min}$ ) followed by a tonic contraction. The magnitude of the tonic contractions was about $8,4,0.7$, and $1 \mathrm{~g}$, respectively. In the case with the aorta, the excess $K$ produced a gradual contraction reaching a maximum (about $1 \mathrm{~g}$ ) after $20 \mathrm{~min}$ (Fig. 1). When high-K solution was exchanged with normal PSS or with a Ca-free high-K solution, the developed tension declined to the original level.

The effects of solutions containing 5.4 to
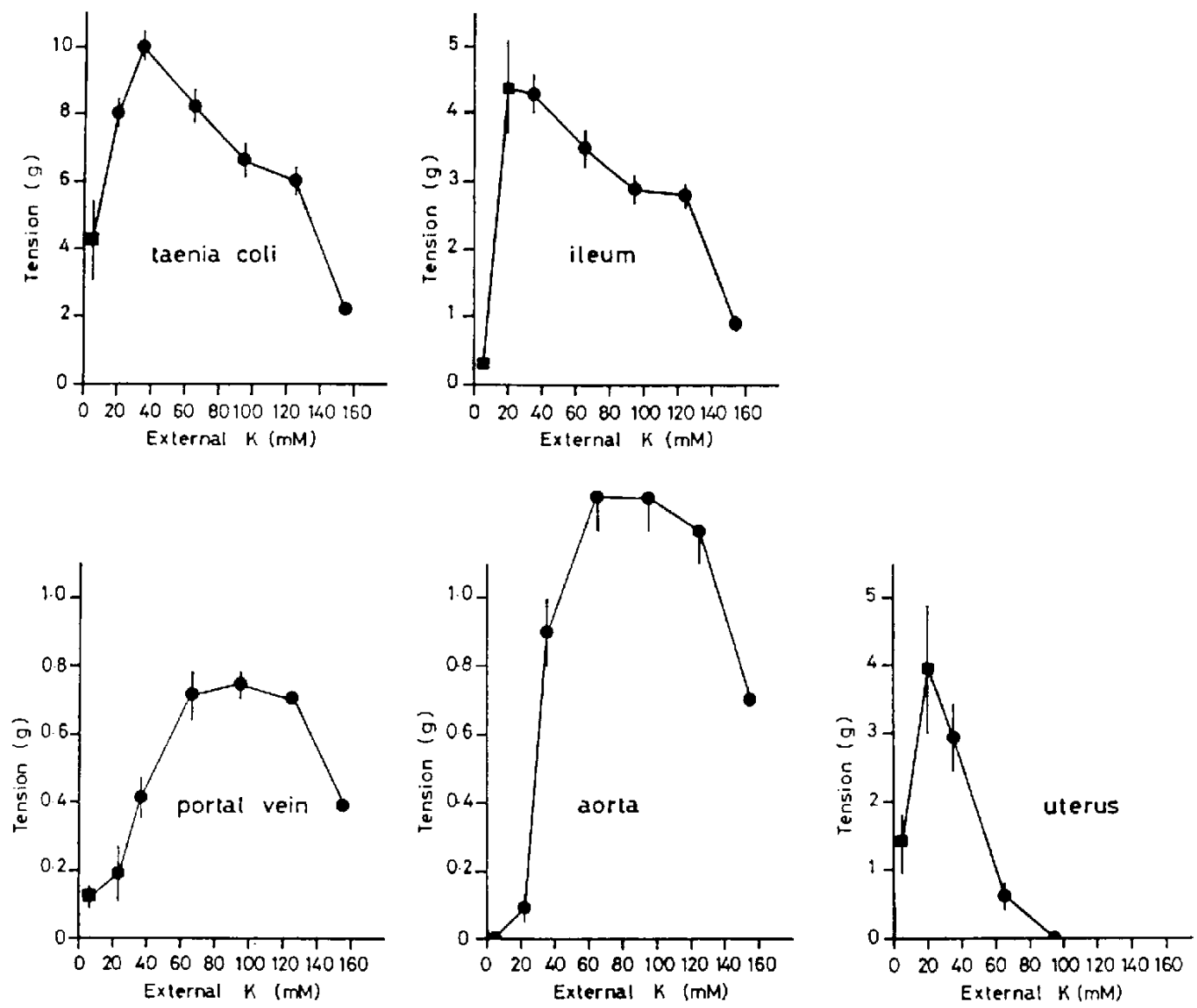

Fig. 2. Effects of excess $K$ on the mechanical activities of the taenia coli, ileum, portal vein. aorta, and uterus. The solution of excess $\mathrm{K}$ was prepared by replacing $\mathrm{NaCl}$ or $\mathrm{NaHCO}_{3}$ with equivalent amounts of $\mathrm{KCl}$ or $\mathrm{KHCO}_{3}$ up to $154.1 \mathrm{mM}$, isotonically. Square symbols represent the mean values of spontaneous contractions for 20 min. Circle symbols represent the magnitude of tonic contraction. In the ileum and uterus, $20.3 \mathrm{mM} \mathrm{K}$ enhanced the spontaneous contraction, but did not produce a tonic contraction. Ordinate: tension ( $g$ ). Abscissa: external $K$ conceration ( $m M$ ). Given are the mean values $\pm S . E . M$. as vertical bars of $4-6$ experiments. 
$154.1 \mathrm{mM} \mathrm{K}$ on the mechanical activity in various smooth muscle preparations of the guinea-pig were investigated. Figure 2 shows the magnitude of the tonic contraction obtained by raising external $\mathrm{K}$ isotonically in the taenia coli, ileum, portal vein, aorta, and uterus. Also, tension curves relative to the hypertonic $K$ concentration $(10-80 \mathrm{mM})$ were almost superimposed on those of the isotonic examination, although the results are not shown. In the taenia coli and ileum. maximal tonic contractions (about $10 \mathrm{~g}$ and $4.5 \mathrm{~g}$. respectively) were produced by external $K$ concentration in the range of 20 to $35 \mathrm{mM}$. Progressive elevation in $\mathrm{K}$ concentration $(60-120 \mathrm{mM})$ resulted in a concomitant depression of the tonic component. These observations may be explained tentatively by partitioning the source of $\mathrm{Ca}$ nessesary for the $\mathrm{K}$-induced tonic contraction to two processes: 1. activation of the $\mathrm{Ca}$ channel involved in spike generation and 2 . the influx of extracellular or superficially bound $\mathrm{Ca}$ following depolarization of the membrane (i.e., depolarization induced $\mathrm{Ca}$ influx). At a higher $K$ concentration than $60 \mathrm{mM}$. the Ca spike disappears beyond the threshold of the depolarization block (11). Therefore, such a contraction is smaller than that associated with the high spike frequency in $20-35 \mathrm{mM} \mathrm{K}$.

In the portal vein and aorta the K-induced contractions were graded in the range of 20-60 $\mathrm{mM}$, reaching the maximum (about $0.7 \mathrm{~g}$ and $1.2 \mathrm{~g}$, respectively) between 60$120 \mathrm{mM}$. It is likely that these vascular smooth muscle tissues have little or no contribution from the $\mathrm{Ca}$ spike during the $\mathrm{K}$-contraction. In the uterus, the maximal tension (about $4 \mathrm{~g}$ ) was, similarly to intestinal smooth muscles, produced in the range of 20 to $35 \mathrm{mM} \mathrm{K}$, but further progressive elevation of $K$ concentration completely suppressed the tonic contraction. The maintained tension response of the uterus may be dependent on $\mathrm{Ca}$ spike discharges rather than the depolarization induced $\mathrm{Ca}$ influx.

Furthermore, in all the smooth muscles, a complete substitution of $\mathrm{K}$ for $\mathrm{Na}$ attenuated the developed tonic contraction, and almost no antagonization of the inhibition was obtained by raising the external $\mathrm{Ca}$ up to $10 \mathrm{mM}$. These inhibitions may be atributable to a $\mathrm{Na}$ deficiency, according to the suggestion that the $\mathrm{Na}$ deficiency causes an inhibition of glucose utilization in the taenia coli (12) or swelling in the aorta (13). leading to muscle relaxation. From the above, it appears that the smooth muscle tissues of functionally different types show a wide range variability with respect to the sensitivity of muscle tension to excess $K$. Therefore, we have made an investigation using the K-contraction induced by $62.7 \mathrm{mM}$ $\mathrm{K}(118.7 \mathrm{mM} \mathrm{NaCl})$ in order to minimize the contribution of the $\mathrm{Ca}$ spike and to evaluate K-depolarization induced $\mathrm{Ca}$ influx.

Furthermore, the effects of various concentrations of $\mathrm{K}$ were investigated in the presence of cholinergic and adrenergic antagonists since high $\mathrm{K}$ is known to release neurotransmitters from nerve endings. The tension changes by high $\mathrm{K}$ were almost unaffected by atropine $\left(2 \times 10^{-6} \mathrm{M}\right)$, phentolamine $\left(2 \times 10^{-6}\right.$ $\mathrm{M})$, and proplanolol $\left(2 \times 10^{-6} \mathrm{M}\right)$ in alt the preparations used.

B. Effect of Li-substitution on K-contractions: The effect of partial Li-substitution for external $\mathrm{Na}$ on the tonic contractions of various smooth muscle tissues depolarized by high-K (62.7 $\mathrm{mM})$ solution was investigated. Half the concentration of external $\mathrm{Na}$ was replaced isosmotically by $\mathrm{Li}$ (59.4 mM) after a 30 min-incubation with high-K solution. These results are shown in Fig. 1. The Li-substitution gradually decreased the developed contractions of the taenia coli, ileum, portal vein, and uterus to $3.9 \pm 0.7, \quad 15.0 \pm 1.3, \quad 20.0 \pm 2.3$, and $30.0 \pm$ 
$2.9 \%(n=6)$ of each control at $50 \mathrm{~min}$. respectively. As shown in Fig. 3, the inhibitory effects were concentrationdependent (23.7 $\mathrm{mM}-59.4 \mathrm{mM})$. In the case with the aorta, however, the $\mathrm{Li}$ substitution failed to inhibit the $\mathrm{K}$-induced contraction or even contractions developed by $\mathrm{K}$ concentrations below $62.7 \mathrm{mM}$.

C. The effects of Li-substitution and verapamil on $\mathrm{Ca}$-induced contractions: The inhibitory effects of Li-substitution on Cainduced contractions in high-K solution were investigated. In Fig. 4, these results are compared with those of verapamil, an organic $\mathrm{Ca}$ antagonist. Cumulative addition of $\mathrm{Ca}(0.25 \mathrm{mM}-10.0 \mathrm{mM})$ produced graded contractions in all the muscles in $\mathrm{Ca}$ depleted high-K medium, suggesting that the K-contractions are strictly external Cadependent. Li-substitution was applied $90 \mathrm{~min}$ before and during the application of $\mathrm{Ca}$, while verapamil was applied $20 \mathrm{~min}$ before. In the taenia coli, ileum, portal vein and uterus, Li-substitution (35.6 $\mathrm{mM})$ shifted the $\mathrm{Ca}$ concentration-response curves towards the right. Also, verapamil $\left(5 \times 10^{-8}\right.$
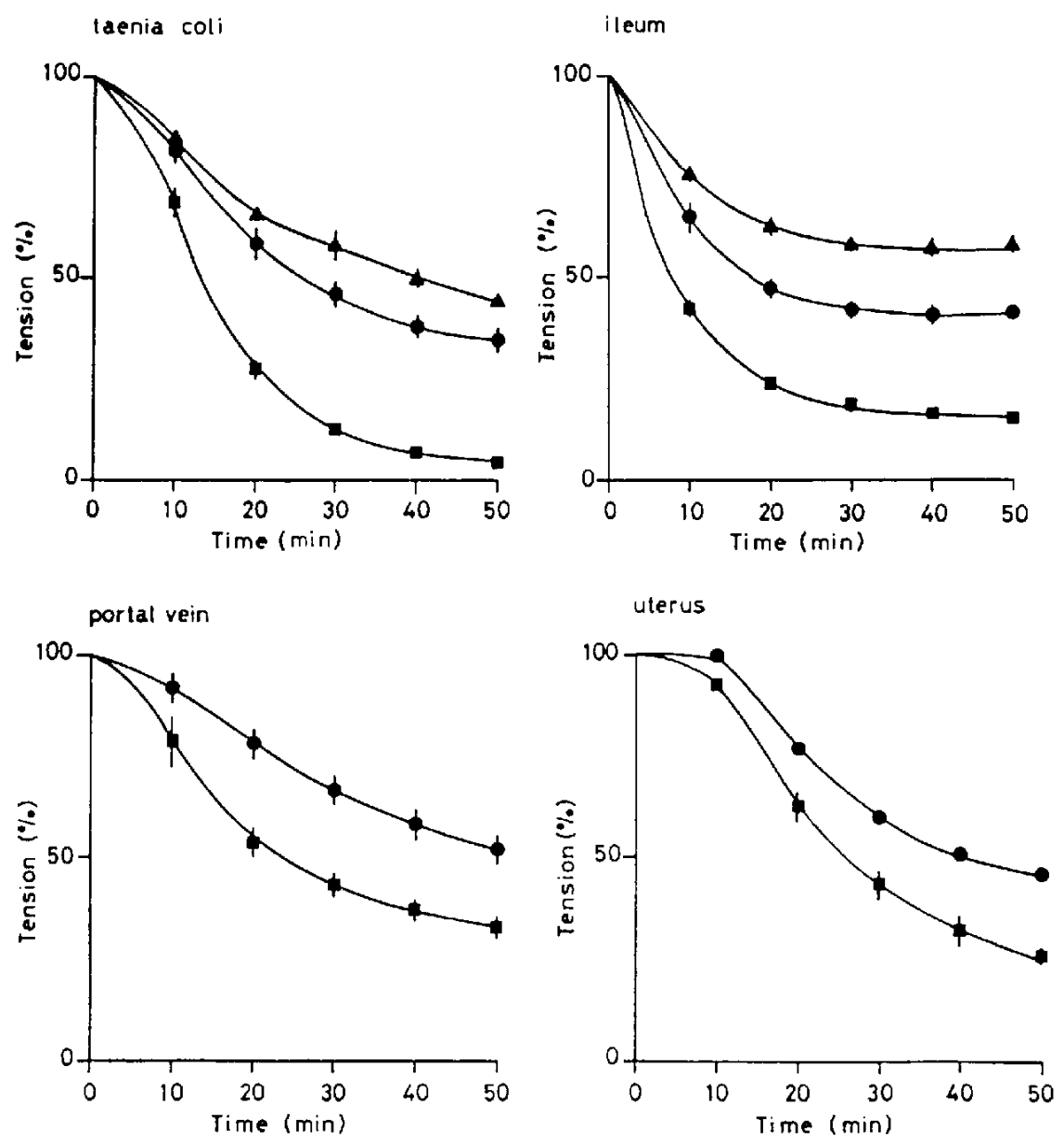

Fig. 3. Concentration-dependent inhibition of K-contraction by Li-substitution in the taenia coli. ileum. portal vein, and uterus. Ordinate: relative tension (\%) of control. Abscissa: time $(\mathrm{min})$ of exposure to $\mathrm{Li}(\boldsymbol{\Delta}), 23.7 \mathrm{mM}:-35.6 \mathrm{mM}: 59.4 \mathrm{mM})$. Given are the mean values \pm S.E.M. for $4-6$ experiments. 

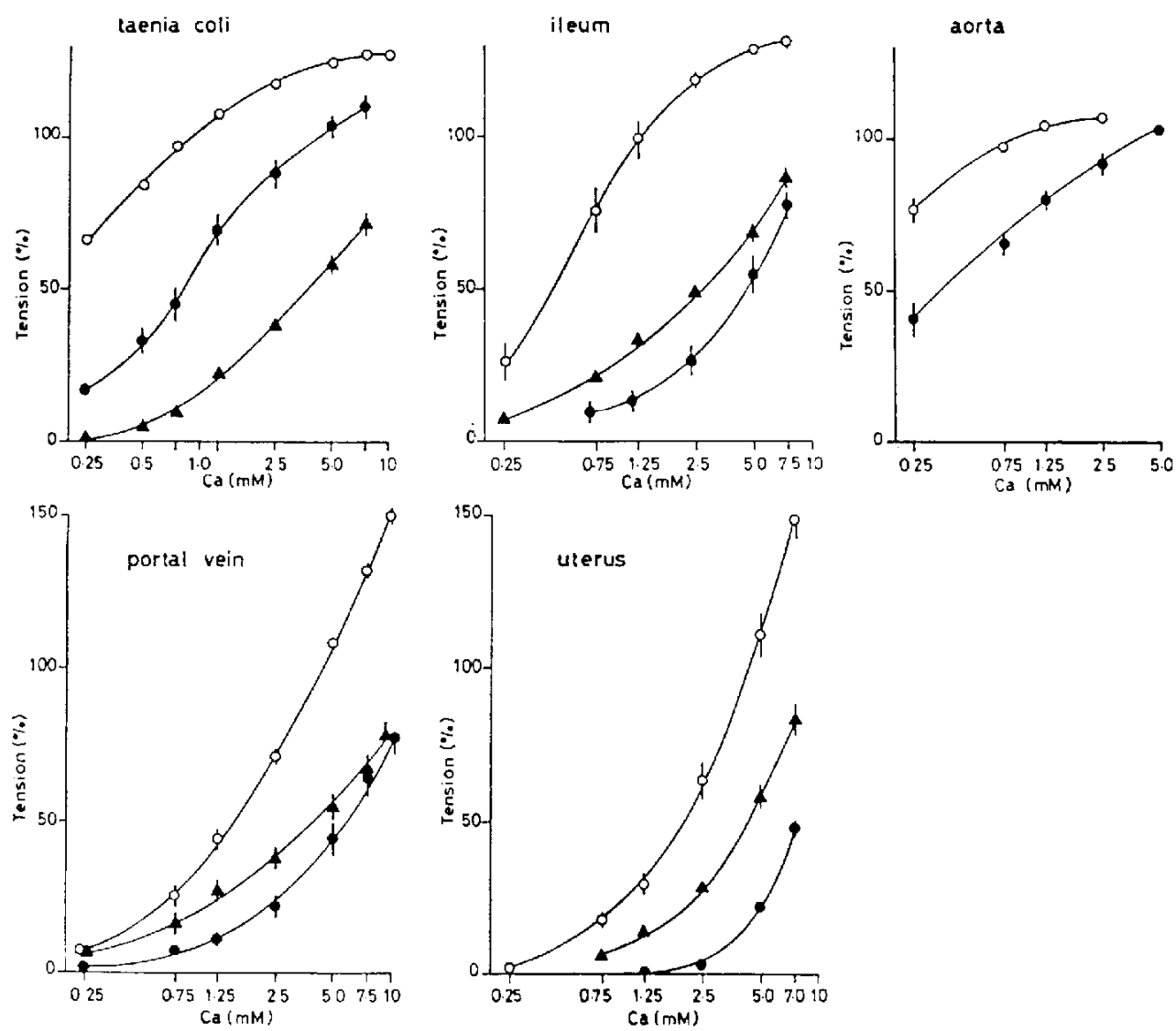

Fig. 4. Effects of Li-substitution and verapamil on the contraction evoked by adding Cacumulatively to the various tissues incubated in Ca-free high-K solution for $2 \mathrm{hr}$. The relative tension expressed as a percent of the $K$-contraction ( $\mathrm{Ca} .2 .5 \mathrm{mM}$ ), is plotted on the ordinate as a function of external Ca concentration on the abscissa. The tissues were pretreated with Li-substitution ( $\mathbf{A} .35 .6 \mathrm{mM}$ ) for $90 \mathrm{~min}$ or with verapamil $\left(\mathbf{S} .5 \times 10^{-8} \mathrm{M}\right.$ ) for $20 \mathrm{~min}$. The control points are represented by open circles. Given are the mean values \pm S.E.M. as vertical bars of 4-12 experiments.

M) showed similar results in all the muscles. Therefore, the inhibitory effect of Li-substitution is antagonized by external $\mathrm{Ca}$, probably indicating that it interacts at a site directly involved with $\mathrm{Ca}$ binding and (or) translocation. This site is presumably the $\mathrm{Ca}$ channel which is activated by high-K induced depolarization.

D. Relationship between cellular $\mathrm{Li}$ and tension: Possible changes in the size of the extracellular space (ECS) were investigated. As shown in Table 1, the size of the ECS in all the muscle preparations was almost unaffected by $59.4 \mathrm{mM}$ Li-substitution in high-K solution. In high-K solution, the dry weight/wet weight ratios in the taenia coli. ileum, portal vein, aorta, and uterus were $21.9 \pm 0.2 \quad 21.4 \pm 0.2, \quad 25.7 \pm 0.7, \quad 25.0 \pm 1.3$. and $20.0 \pm 1.3 \%(n=5)$, respectively.

The changes in cellular $\mathrm{Li}$ concentration of these muscles following $50 \%$ replacement of $\mathrm{Na}$ with $\mathrm{Li}$ in high-K solution were investigated. As shown in Fig. 5A, the Lisubstitution produced a gradual increase in cellular $\mathrm{Li}$ in all the preparations examined. After $250 \mathrm{~min}$, the maximum concentration 
Table 1. Effects of Li-substitution on the size of the ECS during K-contractions in the taenia coli, ileum, portal vein, aorta, and uterus. The tissues were incubated in high-K solution with or without $59.4 \mathrm{mM} \mathrm{Li}$ for $60 \mathrm{~min}$. For the last $20 \mathrm{~min}$, they were exposed to the radioactive solution with ${ }^{14} \mathrm{C}$-sorbitol. Numbers in the parentheses indicate the number of experiments. Given are the meanstS.E.M. There were no significant differences between the sizes of the ECS of the tissues incubated in high-K solutions with and without Li.

\begin{tabular}{lrrr}
\hline Extracellular space $\left({ }^{14 \mathrm{C} \text {-sorbitol. \%) }}\right.$ & & \\
& Normal PSS & High-K solution & High-K+Li \\
\hline & $(4)$ & $(8)$ & $(4)$ \\
Taenia coli & $31.2 \pm 1.5$ & $33.7 \pm 1.9$ & $35.2 \pm 0.9$ \\
lieum & $34.5 \pm 1.5$ & $35.3 \pm 1.9$ & $41.3 \pm 1.9$ \\
Portal vein & $48.4 \pm 2.9$ & $55.5 \pm 1.8$ & $60.7 \pm 3.4$ \\
Aorta & $57.7 \pm 1.5$ & $56.2 \pm 1.4$ & $54.8 \pm 3.0$ \\
Uterus & $54.2 \pm 2.2$ & $51.7 \pm 2.7$ & $57.3 \pm 1.4$ \\
\hline
\end{tabular}

of Li accumulation reached in the taenia coli. ileum, portal vein, aorta, and uterus were $71.8 \pm 4.5, \quad 65.8 \pm 4.6, \quad 73.8 \pm 5.2, \quad 69.1 \pm 2.1$. and $58.0 \pm 4.6 \mathrm{mmol} / \mathrm{l}$ cell water $(n=4)$. respectively. Figure $5 \mathrm{~B}$ demonstrates the relationship between the increase in cellular $\mathrm{Li}$ and tension. In the taenia coli, ileum. porta! vein, and uterus, a correlation was obtained between cellular $\mathrm{Li}$ concentation and inhibition of tension. The cellular $\mathrm{Li}$ concentrations to inhibit K-contractions of the taenia coli, ileum, portal vein, and uterus by $50 \%$ were approximately $21.2,19.0,32.5$, and $56.5 \mathrm{mmol} / \mathrm{l}$ cell water, respectively. In the aorta, however, no correlation was seen.

E. Change in cellular ${ }^{45} \mathrm{Ca}$ content: The effect of Li-substitution on the K-induced increase in cellular $\mathrm{Ca}$ content was investigated. These results are shown in Fig. 6. Muscle strips were incubated in high-K solution with or without $59.4 \mathrm{mM}$ Li for $60 \mathrm{~min}$, and then they were transferred to the radioactive solution. After loading with ${ }^{45} \mathrm{Ca}$ for $30 \mathrm{~min}$, the cellular ${ }^{45} \mathrm{Ca}$ content was measured by a modified "Lamethod". In high-K solution, " $\mathrm{C}$ a uptake of the taenia coli, ileum and aorta increased significantly compared with those in normal solution. In the case with the uterus, we

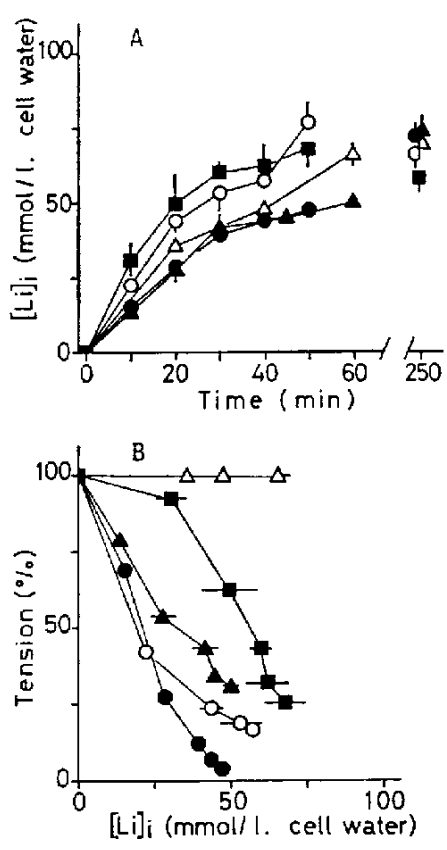

Fig. 5. A: Changos in cellular Li concentration induced by Li-substitution in $\mathrm{K}$-depolarized preparations of the taenia coli (O). ileum (O). portal vein $(\boldsymbol{\Delta})$, aorta $(\Delta)$, and uterus ( $\mathbf{D}$ ). Ordinate: cellular $\mathrm{Li}$ concentration (mmol/l cell water). Abscissa: time (min) of exposure to $59.4 \mathrm{mM}$ Li. B: Relationship between cellular Li concentration and tension. Ordinate: relative tension (\%). Abscissa: cellular Li concentration (mmol/l cell water). The symbols are the same as for A. Given are the mean values $=$ S. E.M. for 4-8 determinations. 


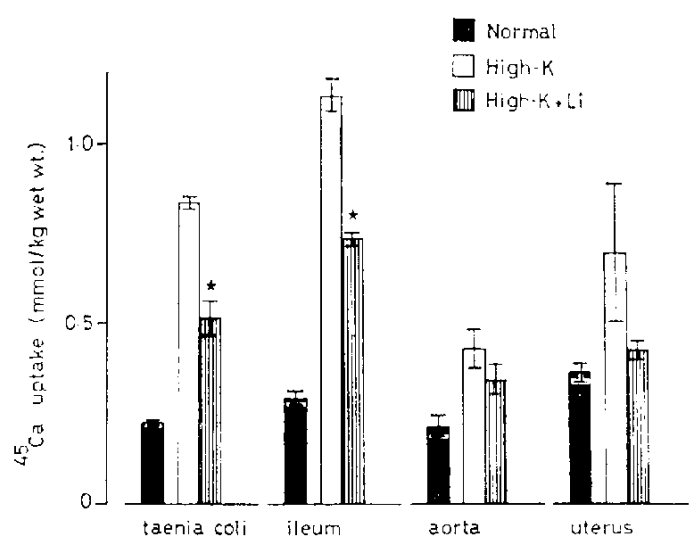

Fig. 6. Effect of Li-substitution on ${ }^{25} \mathrm{Ca}$ uptake during $K$-contraction in the taenia coli. ileum. aorta, and uterus. The tissues were troated with $59.4 \mathrm{mM} \mathrm{Li}$ for $60 \mathrm{~min}$ boforo ard during cxposure to the radioactive solutions. The ${ }^{45} \mathrm{Ca}$ uptake period was $30 \mathrm{mir}$. Tho vertical bars represent-S.E.M. for $4-8$ dotaminations.

*: Significantly different from the value in tigh K solution (P<0.05).

could not obtain a significant increase in ${ }^{45} \mathrm{Ca}$ content by high- $K$ solution becausc of the large variation. The $\mathrm{K}$-induced ${ }^{\mathrm{C}} \mathrm{Ca}$ uptake was attenuated by Li-substitution in the taenia coli. ileum and uterus but not in the aorta. These results seem to be in good accord with those of the tension experiment. The result with the portal vein could not be shown because of the scattering of the data obtainod.

\section{DISCUSSION}

Previous studies have shown that whon Li is partially substituted for $\mathrm{Na}$ in high-K solution, the developed tension of guineapig taenia coli gradually decreased to the original level (1-4). It has also been reported that the $\mathrm{Ca}$-induced contractile response was inhibited by a partial substitution with Li for $\mathrm{Na}$ in high-K solution in the longitudinal and circular muscles of guinea-pig stomach (5) and in rat uterus (7). In addition. Freer and Smith (6) reported that $\mathrm{Li}$ inhibited angiotensin II and acetylcholine contraction. suggesting that Li may be a specific inhibitor in uterine tissue.

Our recent study (8) suggests that Lisubstitution which inhibits the tonic contraction of the taenia coli depolarized by high $K$ has the following properties: 1) no effect on K-induced membrane depolarization 2) the dependence of the inhibitory effect on the concentration of Li-substitution, 3) the devendence on the length of the period of application of Li-substitution, 4) the correlation between the accumulation of cellular $\mathrm{Li}$ and the inhibition, 5) the antagonization by raising external $\mathrm{Ca}$ and 6 ) the inhibition of ${ }^{15} \mathrm{Ca}$ uptake. These findings indicate that the action of $\mathrm{Li}$ is closely related to an accumulation of intracellular Li; the possible mechanism involved is to inhibit $\mathrm{Ca}$ influx in response to depolarization with high $K$. As shown in the present results, the inhibitory effect of Li-substitution was antagonized by raising external $\mathrm{Ca}$ concentration in guineapig taenia coli, ileum, portal vein, and uterus. It was also associated with a decrease in cellular ${ }^{45} \mathrm{Ca}$ content, although we can not exoress these relationstips quantitatively. Freer and Smith $(6,7)$ have speculated that extracellular Li, similarly to a $\mathrm{Ca}$ antagonist, competes with $\mathrm{Ca}$ for binding to negative sites or the cell surfaco, since an increase in external $\mathrm{Ca}$ attenuates the inhibition. However, it is difficult to consider that external $\mathrm{Li}$ reduces $\mathrm{Ca}$ influx by competing with $\mathrm{Ca}$ for influx sites in the membrane since the rolaxation caused by Li-substitution was dependent on the duration of the exposure to Li. From the above, a possibility exists that excess cellular $L i$ inhibits $K$ induced $\mathrm{Ca}$ influx in the several smooth muscle tissues of guinea pigs. However, the inability of Li to inhibit K-contraction in the aorta may reflect a basic difference in the mechanisms of $\mathrm{Ca}$ utilization in the aorta relative to the other muscles as well as a possible inhibitory action of $L i$ unrelated to 
Ca transport ability induced by K-depolarization.

The relationship between cellular Li concentration and relaxation obtained from the experimental results with the ileum resembles closely what was observed in the taenia coli. However, the cellular Li concentration in the portal vein or uterus to inhibit K-contraction by $50 \%$ was higher than that required with the taenia coli. It also seems that K-induced $\mathrm{Ca}$ influx in the aorta is almost insensitive to the inhibitory effect of cellular Li. Thus, there is a tissue-specific difference in the sensitivity to $\mathrm{Li}$ and the order is guinea-pig taenia coli, ileum $\geq$ portal vein>uterus $\gg$ aorta. On the other hand, the present results indicate that contractile responses to various $K$ concentrations are rather different among intestinal, vascular, and uterine smooth muscles. These contractile activities seem to be more dependent upon depolarizationinduced $\mathrm{Ca}$ influx than $\mathrm{Ca}$ spike discharge in the following order: uterus >taenia coli, ileum>portal vein, aorta. However, this difference is incompatible with the order of the tissue-specific difference in the sensitivity to $\mathrm{Li}$. We have also reported that the order of the tissue-specific difference in the sensitivity to verapamil is uterus>portal vein, ileum, taenia coli>aorta, reflecting the dependence on external $\mathrm{Ca}$ for $\mathrm{K}(62.7$ $\mathrm{mM}$ )-contractions of these tissues (9). Therefore, the property of the tissue- specific difference on the inhibitory effect of $\mathrm{Li}$ is dissimilar to verapamil, but is similar to the case with ouabain (9).

In the preceding paper (9), we have reported that the ouabain-induced inhibition of K-contractions of the taenia coli, ileum, portal vein, and uterus is explained by the increased intracellular $\mathrm{Na}$ which would inhibit the K-induced increase in $\mathrm{Ca}$ influx. The cellular $\mathrm{Na}$ concentrations to inhibit $\mathrm{K}$ contractions of the taenia coli and ileum by $50 \%$ are about 62.5 and $60.0 \mathrm{mmol} / \mathrm{l}$ cell water, respectively. The cellular Li concentrations to inhibit by $50 \%$ are about 21.2 and $19.0 \mathrm{mmol} / \mathrm{l}$ cell water, respectively. Thus, the inhibitory effect of cellular $\mathrm{Li}$ is greater than that of cellular Na. Although the difference of the potency between the two ions is difficult to interpret, the binding tendency of Li by many ligands is preferential to that of $\mathrm{Na}$ according to stoichiometric stability constants. Cellular $\mathrm{Na}$ and Li appear to interact at a common site (14). If so, the tendency of $\mathrm{Li}$ to combine with the sites involved in the inhibitory action would bo greater than the tendency of $\mathrm{Na}$.

In conclusion, Li-substitution inhibited K-contraction in guinea-pig taenia coli. iloum, portal vein, and uterus but not in the aorta. The inhibition was closely related to an accumulation of intracellular $\mathrm{Li}$ which would cause relaxation by inhibiting $K$ depolarization induced $\mathrm{Ca}$ entry. It is also suggested that the inhibitory effect of cellular $\mathrm{Li}$ is greater than that of cellular $\mathrm{Na}$. However. there is a tissue-specific difference in the sensitivity to $\mathrm{Li}$, and the cause should be further investigated.

Acknowledgement: This study was supportod in part by research grant No. 556198 from the Ministry of Education. Science and Culture, Japan.

\section{REFERENCES}

1) Pfaffman, M., Urakawa, N. and Holland, W.C.: Role of motabolism in K-induced tension changes in guinea pig taenia coli. Am. J. Physiol. 208, 1203-1205 (1965)

2) Ganeshanandan, S.S., Karaki, H., Ikeda, M. and Urakawa, N.: Mechanical response of guinea pig taenia coli in high-K/Na deficient medium under anoxia. Japan. J. Pharmacol. 19, 329330 (1969)

3) Karaki, H., Ganeshanandan, S.S., Ikeda, M. and Urakawa, N.: Changes in tension, Ca movement and metabolism of guinea pig taenia coli in varying concentrations of external $\mathrm{Na}$ and $\mathrm{K}$. Japan. J. Phamacol. 19, 569-577 (1969)

4) Urakawa, N., Karaki, H. and Ikeda, M.: Effects of ouabain and metabolic inhibiting factors on 
Ca distribution during K-induced contracture in guinea pig taenia coli. Japan. J. Pharmacol. 20, 360-366 (1970)

5) Ishizawa, M. and Miyazaki, E.: Differences between $\mathrm{Ca}$ contractures in the depolarized longitudinal and circular muscles of guinea pig stomach. Japan. J. Physiol. 29, 75-83 (1979)

6) Freer, R.J. and Smith, A.B.: Effects of lithium on responsiveness of rat uterine smooth muscle to anginotensin. Am. J. Physiol. 230, 1132-1137 (1976)

7) Freer, R.J. and Smith, A.B.: Lithium dissociation of calcium- and angiotensin induced contracitons in depolarized rat uterus. Am. J. Physiol. 236, 171-176 (1979)

8) Kishimoto, T. and Urakawa, N.: The inhibitory effect of lithium on high-K induced contraction in guinea-pig taenia coli. Naunyn-Schmiedeberg's Arch. Pharmacol. 315, 69-76 (1980)

9) Kishimoto, T. and Urakawa, N.: Effects of ouabain on high-K induced contractions of various smooth muscle tissues in the guineapig. Japan. J. Pharmacol. 32, 551-561 (1982)
10) Karaki, H. and Weiss, G.B.: Alteration in high and low affinity binding of $45 \mathrm{Ca}$ in rabbit aorta by norepinephrine and potassium after exposure to lanthanum and low temperature. J. Pharmacol. exp. Ther. 211, 86-92 (1979)

11) Shimo, Y. and Holland, W.C.: Effects of potassium on membrane potential, spike discharge and tension in taenia coli. Am. J. Physiol. 211, 1299-1304 (1966)

12) Suzuki, T., Karaki, H. and Urakawa, N.: Mechanism of inhibition of contraction by high $\mathrm{K}$. Na deficient solution in smooth muscle of guineapig taenia coli. Archs int. Pharmacodyn. Thér. $248,43-49$ (1980)

13) Suzuki, T., Karaki, H. and Urakawa, N.: Inhibition of contraction by swelling of vascular smooth muscle in high $\mathrm{K}$. low $\mathrm{Na}$ solution. Archs int. Pharmacodyn. Thér. 250, 195-203 (1981)

14) Frausto da Silva, J.J.R. and Williams, R.J.P.: Passible mechanism for the biological action of lithium. Nature 263, 237-239 (1976) 